\title{
ROLE OF L: METHYLFOLATE WITH ESCITALOPRAM FROM TREATMENT INITIATION IN DEPRESSION
}

\author{
Pali Rastogi', Sapna Gajbhiye More ${ }^{2}$, Pradeep Phadnis ${ }^{3}$,Ramghulam Razdan', Savita Vyas 5 , R. P. Agrawal 6 \\ ${ }^{1}$ Assistant Professor, Department of Psychiatry, M. Y. H. Hospital, Indore. \\ ${ }^{2}$ Assistant Professor, Department of Pharmacology, Dr. D. Y. Patil Medical College \& Research Center, Pimpri, Pune. \\ ${ }^{3}$ Associate Professor, Department of Pharmacology, M. G. M. Medical College, Indore. \\ ${ }^{4}$ Professor, Department of Psychiatry, M. Y. H. Hospital, Indore. \\ ${ }_{5}^{5}$ Associate Professor, Department of Pharmacology, M. G. M. Medical College, Indore. \\ ${ }^{6}$ Professor, Department of Pharmacology, M. G. M. Medical College, Indore.
}

\begin{abstract}
BACKGROUND: Patients suffering from depressive episode show incomplete response despite proper use of antidepressants. This could be due to variety of factors. One factor of utmost importance is low CNS and serum folate levels.

AIMS: Evaluate the efficacy of L -methylfolate in combination with Escitalopram compared to Escitalopram monotherapy in moderate to severe depressive patients.

SETTINGS AND DESIGN: Observational study of L-methylfolate plus Escitalopram at treatment initiation $(\mathrm{n}=30)$ and Escitalopram monotherapy $(\mathrm{n}=30)$ at outdoor patient department.

METHODS AND MATERIAL: 30 patients of moderate to severe depressive episode were enrolled in each group. All the patients were evaluated for response and side effects on 14,21, 45, 60 days on Hamilton depression rating scale and adverse drug reaction proforma.

STATISTICAL ANALYSIS: Mann Whitney test.

RESULTS: Major improvement was experienced by $96.7 \%$ of L-methylfolate plus Escitalopram group compared to $46.7 \%$ of Escitalopram monotherapy group. Response as early as 14 days were reported by $20 \%$ patients in combination group. There was no significant differences between groups in adverse events. Conclusion: L-methylfolate plus Escitalopram at treatment onset was more effective, well tolerated in improving depressive symptoms.
\end{abstract}

KEYWORDS: L-methylfolate (L-MTF), Escitalopram, Depression.

HOW TO CITE THIS ARTICLE: Pali Rastogi, Sapna Gajbhiye More, Pradeep Phadnis, Ramghulam Razdan, Savita Vyas, R. P. Agrawal. "Role of L: Methylfolate with Escitalopram from Treatment Initiation in Depression". Journal of Evolution of Medical and Dental Sciences 2015; Vol. 4, Issue 88, November 02; Page: 15275-15278, DOI: 10.14260/jemds/2015/2171.

INTRODUCTION: Major depressive disorder (MDD) currently ranks fourth leading disease burden world-wide and is expected to become second global disease burden in $2020 .{ }^{1}$ Though it is viewed as one of the most treatable conditions, it tends to be recurrent. ${ }^{2}$ The sequenced treatment alternatives to relieve depression (STAR*D) study demonstrated disappointing remission rates (30\%) for initial antidepressant monotherapy and disappointing rates of not maintaining remission $(>70 \%)$ attained by the first agent. ${ }^{3,4,5}$ Administering combination or adjunctive agents. at the initiation of treatment in lieu of sequenced treatment trials represents a major paradigm shift in the treatment of MDD. ${ }^{6}$ Six clinical trials suggest that combinations from the start of treatment may lead to more rapid clinical outcomes, higher remission rates and lower relapse rates when compared with sequentially administered single antidepressants. ${ }^{7-12}$

Evidence from the open and blinded studies have demonstrated the efficacy of Methyl-tetrahydrofolate in combination with anti-depressants at the initiation of therapy or as monotherapy in depressed patients with normal and low folate levels. ${ }^{10,13-15}$

Financial or Other, Competing Interest: None.

Submission 17-10-2015, Peer Review 19-10-2015,

Acceptance 21-10-2015, Published 30-10-2015.

Corresponding Author:

Dr. Pali Rastogi,

68- Mangalmurtikrishnaji Nagar, Scheme-77,

(Behind Mayur Hospital), Bengali Square, Indore-452016, M. P.

E-mail:dr.palirastogi73@gmail.com

DOI:10.14260/jemds/2015/2171.
L-Methylfolate (L-MTF), the bioavailable form of folate is required in the central nervous system to aid in the synthesis of monoamines. ${ }^{16}$

Subotimal serum, red blood cell folate levels and C.N.S. folate status have been associated with more severe symptoms of depression, poorer response to antidepressant drugs, longer duration of illness, later onset of clinical improvement and greater treatment resistance. ${ }^{17-24}$ Depressive episodes are also linked with the common inborn error of metabolism associated with reduced L-MTF. This inborn error is the $\begin{array}{lll}\text { Methyltetrahydrofolate reductase } & \text { (MTHFR) }\end{array}$ polymorphism. ${ }^{25-26}$

To see the effect of L-MTF it must be used with an antidepressant. The present observational study was done on Escitalopram, an antidepressant widely used, easily available, safe and class (SSRI) representative. The study asses the clinical outcome and tolerability in patients receiving combination of L-MTF plus Escitalopram at the initiation of treatment compared with Escitalopram monotherapy.

MATERIAL \& METHODS: Sample - The study included the patients attending the psychiatry outpatient clinic at M.Y.H. Hospital - M.G.M. Medical college Indore.

INCLUSION \& EXCLUSION CRITERIA: The patients aged 1860 years, newly diagnosed as Depression, having moderate to severe severity as per ICD-10 criteria. ${ }^{27}$ were taken for the study after informed consent. Patients taking supplemental folic acid, having current or a history of psychotic episodes, history of bipolar disorder, patient with suicidal tendencies or the patients having significiant physical and neurological illness were excluded from the study. 
Method of Study: The patients who full filled the selection criteria were included in the study. Semi structured proforma and HDRS (Hamilton depression rating scale) was administered.

Patients were divided in two groups based on the observation, one group was of L-MTF plus Escitalopram and other was of Escitalopram alone. The score was calculated for both the groups. The assessment on HDRS was done again in the follow up at $14,21,45 \& 60$ days. $50 \%$ or more reduction in HDRS was considered as response. Adverse drug reaction were noted as per the proforma.

\section{Statistical Analysis: \\ Mann Whitney's Test:}

RESULT: The sample consisted of 60 patients, 30 in each group; with the mean age of 37 years in Escitalopram group and 32.23 years in combination group No significant sex differentiation was observed in two groups. The average duration of illness was comparable in both groups. The dosages of Escitalopram used in both the groups were similar.

DISCUSSION: The present study demonstrated that by adding L-MTF to Escitalopram at the initiation of treatment led to greater number of responders comparison to Escitalopram monotherapy. This number was almost twice more than the Escitalopram group.

The finding of significant greater response was replicated in six controlled studies but they have used combination of two anti-depressants rather than combination of Escitalopram and L methylfolate used in the present study. ${ }^{7-12}$ Coopen $A$ et al found similar results using Fluoxetine with folic acid. ${ }^{28}$

Our study has used L-MTF, biologically active form of folate and the only form that crosses blood brain barrier. Study by Lawrence $\mathrm{D}$ et al also demonstrated major improvement in depressive symptoms and functions in LMTF plus SSRI or SNRI from treatment initiation, compared to SSRI or SNRI monotherapy. ${ }^{29}$

However our observation is only on Escitalopram making it more class specific (Only SSRI) and even no intraclass variation among SSRIs could have affected the result.

Additionally 20\% patients on L-MTF plus Escitalopram had response as early as 2 weeks. The findings were similar to Lawrence D et al who found time for major improvement in combination group was $23 \%$ shorter than monotherapy. ${ }^{29}$ the reason for rapid improvement could be the synergistic action of Escitalopram and L-MTF. L- MTF may facilitate a more rapid response to reuptake inhibitors by regulating upstream synthesis of serotonin, nor epinephrine and dopamine sufficiently to help achieve and maintain 'Downstream' response of reuptake inhibition. ${ }^{30}$

Another reason could be because $70 \%$ of the patients with the MTHFR polymorphism may have reduced CNS LMTF level. ${ }^{26}$ thus the patient given L-MTF from the initiation of therapy achieved better results. All adverse events in both groups were mild and tolerable. No drop outs were reported in both the groups due to adverse events.

LIMITATIONS: The present study is limited by being open lable and non-randomized. Only Escitalopram is being used in present study. More studies with other SSRI's and other classes are required to validate the findings. Folate levels at base line could have given more definite results.
CONCLUSIONS: The study shows improvement and rapid response when L-MTF was added to Escitalopram from initiation.

It paves way for further research in the quest to achieve early response and full remission in depressed patients.

\section{REFERENCES:}

1. Hyman S, Chisholm D, Kessler R, et al. Mental disorders. In:Jamison DT,Breman JG, Measham AR, et al. Disease Control Priorities in Developing Countries, Second Edition. New York: Oxford University Press: 2006:591-605.

2. Fava M, Rush AJ. Current status of augmentation and combination treatments for major depressive disorder: a literature review and a proposal for a novel approach to improve practice. Psychother Psychosom.2006; 75(3):139153.

3. Rush JA, Trivedi MH, Wisniewski SR, et al. Acute and longer term outcomes in depressed outpatients requiring one or several treatment steps: a STAR*D report. Am J Psychiatry.2006; 163(11):1905-1917.

4. Trivedi MH, Rush AJ, Wisniewski SR, et al. Evaluation of outcomes with citalopram for depression using management based care in STAR*Implications for clinical practice. Am J Psychiatry.2006; 163(1):28-40.

5. Gaynes BN, Davis L, Rush AJ, et al. The aims and design of the Sequenced Treatment Alternatives to Relieve Depression (STAR*D) study. Psychiatry Res.2006; 141(2):193-200.

6. Stahl S. Combining antidepressant therapies from the initiation of treatment: a paradigm shift for major depression. J Clin Psychiatry. 2009; 70(11):1493-1494.

7. Nelson CJ, Mazure CM, Jatlow PI, et al. Combining norepinephrine and serotonin reuptake inhibition mechanisms for treatment of depression: a double blind randomized study. Biol Psychiatry. 2004; 55(3):296-300.

8. Biler P, Ward HE, Tremblay $P$, et al. Combination of antidepressant medications from treatment initiation for major depressive disorder: a double blind randomized study. Am J Psychiatry.2010; 167(3):281-288.

9. Blier P, Gobbi G, Turcotte JE, et al. Mirtazapine and paroxetine in major depression: a comparison of monotherapy versus their combination from treatment initiation. Eur Neuropsychopharmacol. 2009; 19(7):457465.

10. Goldfrey PS, Toone BK, Carney MW, et al. Enhancement of recovery from psychiatric illness by methylfolate. Lancet. 1990; 336 (8712):392-395.

11. Ebert D, Jasper A, Murata H, Kaschka WP. Initial lithium augmentation improves the antidepressant effects of standard TCA treatment in non-resistant depressed patients. Psychopharmacology (Berl).1995; 118(2):223-225.

12. Fava M, McCall WV, Krystal A, et al. Exzopiclone coadministered with fluoxetine in patients with insomnia coexisting with major depressive disorder. Biol Psychiatry.2006; 59(11):1052-1060.

13. Di Palma C, Urani R, Argicola R, et al. Is methylfolate effective in relieving major depression in chronic alcoholics? a hypothesis of treatment. Curr Ther Res.1994; 55(5):559568. 
14. Guaraldi GP, Fava M, Mazzi F, et al. An open trial of methyltetrahydrofolate in elderly depressed patients. Ann Clin Psychiatry. 1993; (2):101-105.

15. Passeri M, Cucinotta D, Abate G, et al. Oral 5methyltetrahydrofolic acid in senile organic mental disorders with depression: results of double-blind multicenter study. Aging Clin Exp Res. 1993; 5(1):63-71.

16. Stahl SM. Novel therapeutics for depression: Lmethylfolate as a trimonoamine modulator and antidepressant-augmenting agent. CNS Spectr.2007; 12(10):739-44.

17. Wesson VA, Levirr AJ, Joffe RT. Change in folate status with antidepressant treatment. Psychiatry Res.1994; 53(3):313-322.

18. Abou-Saleh MT, Coppen A. Serum and red blood cellfolate in depression. Acta Psychiatr Scand.1989; 80(1):78-82.

19. Alpert M, Silva RR, Pouget ER. Prediction of treatment response in geriatric depression from baseline folate level: Interaction with an SSRI or a tricyclic antidepressant. J Clin Psychopharmacol. 2003; 23(3):309-313.

20. Papakostas GI, Losifescu DV, Renshaw PF, et al. Brain MRI white matter hyperintensities and one-carbon cycle metabolism in non-geriatric outpatients with major depressive disorder (Part II).Psychiatry Res.2005;140(3):301-307.

21. Alpert JE, Fava M. Nutrition and depression: the role of folate. Nutr Rev.1997; 55(5):145-149.

22. Levitt AJ, Joffe RT. Folate, B12, and life course of depressive illness. Biol Psychiatry. 1989;25(7):867-872.
23. Papakostas GI, Petersen T, Lebowitz BD, et al. The relationship between serum folate, Vitamin B12, and homocysteine levels in major depressive disorder and the timing of improvement with fluoxetine. Int J Neuropsychopharmachol. 2005; 8(4):523-528.

24. Coppen A, Bolander-Gouaille C. Treatment of depression: time to consider folic and vitamin B12. J Psychopharmacol.2005; 19(1):59-65.

25. Kelly CB, McDonnell AP, Johnston TG, et al. The MTHFR C677T polymorphism is associated with depressive episodes in patients from Northern Ireland. J Psychopharmacol.2004; 18(4):567-571.

26. Gilbody S, Lewis S, Lightfoot T. Methylenetetrahydrofolate reductase (MTHFR) genetic polymorphisms and psychiatric disorders: A HuGE review. Am J Epidemiol. 2007; 165(1):113.

27. World Health Organisation: Depressive episode In: The ICD 10 classification of mental and behavioural disorders: clinical description and diagnostic guidelines. New Delhi: Oxford University press.1992.

28. Coppen A, Bailey J. Enhancement of the antidepressant action of fluoxetine by folic acid: a randomized, placebo controlled trial. Journal of affective disorders.2000; 60:121130.

29. Lawrence D, Ginsberg MD, Alondra Y, Yahya A.Lmethylfolate plus SSRI or SNRI from treatment initiation compared to SSRI or SNRI monotherapy in a major depressive episode. Innov Clin Neurosci.2011; 8(1):19-28.

30. Delgado P, Moreno F. Antidepressants and the brain. Int Clin Psychopharmacol. 1999; 14 (Suppl 1):S9-16.

\begin{tabular}{|c|c|c|c|c|}
\hline \multirow{3}{*}{$\begin{array}{c}\text { Time } \\
\text { duration }\end{array}$} & \multirow{2}{*}{\multicolumn{2}{|c|}{$\begin{array}{c}\text { Escitalopram } \\
\mathbf{n}=30\end{array}$}} & \multirow{2}{*}{\multicolumn{2}{|c|}{$\begin{array}{c}\text { L-methylfolate plus Escitalopram } \\
n=30\end{array}$}} \\
\hline & & & & \\
\hline & $\begin{array}{c}\text { No. of } \\
\text { responders }\end{array}$ & $\begin{array}{c}\% \text { of } \\
\text { responders }\end{array}$ & $\begin{array}{c}\text { No. of } \\
\text { responders }\end{array}$ & $\begin{array}{c}\% \text { of } \\
\text { responders }\end{array}$ \\
\hline 0 day & 0 & 0 & 0 & 0 \\
\hline 14 day & 1 & 3.3 & 6 & 20 \\
\hline 21 day & 5 & 16.7 & 11 & 36.7 \\
\hline 45 day & 14 & 46.7 & 29 & 96.7 \\
\hline 60 day & 14 & 46.7 & 29 & 96.7 \\
\hline
\end{tabular}

(Parameter evaluated: HDRS $>50 \%$ reduction in scores from day 0)

\begin{tabular}{|c|c|c|c|c|}
\hline Time & $\begin{array}{c}\text { Escitalopram } \\
\text { (HDRS) }\end{array}$ & $\begin{array}{c}\text { L-Methylfolate } \\
\text { + Escitalopram } \\
\text { (HDRS) }\end{array}$ & $\begin{array}{c}\text { Mann-Whitney } \\
\text { U value }\end{array}$ & $\begin{array}{c}\text { (\% of difference) } \\
\text { Inc. in no. of } \\
\text { Responders compared } \\
\text { to escitalopram group }\end{array}$ \\
\hline 0 day & $23.03 \pm 0.73$ & $24.68 \pm 1.20$ & 596.00 & 0 \\
\hline 14 day & $19.60 \pm 0.92$ & $18.90 \pm 1.33$ & 414.50 & 16.7 \\
\hline 21 day & $15.33 \pm 1.05$ & $8.87 \pm 0.76^{*}$ & 146.50 & 20 \\
\hline 45 day & $12.93 \pm 1.02$ & $3.43 \pm 0.67^{*}$ & 55.00 & 50 \\
\hline 60 day & $7.50 \pm 0.67$ & $3.43 \pm 0.67^{*}$ & 146.50 & 50 \\
\hline \multicolumn{5}{|c|}{ Table 2: Hamilton Depression Rating Score, Through the Course of Study } \\
\hline
\end{tabular}

Mann Whitney's test.

Values are mean \pm SEM, $n=30$ in each group.

${ }^{*} \mathrm{P}<0.001$ as compared to escitalopram group. 
Tables shows that L-MTF plus Escitalopram did not demonstrate any significant decrease in HDRS on day 14, but 20\% (n=6) receiving this combination demonstrated response (50\% reduction in HDRS) vs. 3.3\% (n=1) of Escitalopram group.

Further, L-MTF plus Escitalopram group demonstrated significant decrease in HDRS ( $<<0.001)$ at 21,45 and 60 days with $36.7 \%(n=11), 96.7 \%(n=29)$ and $96.7 \%(n=29)$ responders $(50 \%$ reduction in HDRS) compared with Escitalopram monotherapy group $16.7(n=5), 46.7 \%(n=14), 46.7 \%(n=14)$ respectively.

\begin{tabular}{|c|c|c|}
\hline Adverse Events & $\begin{array}{c}\text { Escitalopram } \\
(\mathbf{n = 3 0 )}\end{array}$ & $\begin{array}{c}\text { L-methylfolate plus } \\
\text { Escitalopram } \\
(\mathbf{n}=\mathbf{3 0})\end{array}$ \\
\hline Gastrointestinal disorders & $1(3.33 \%)$ & $3(10 \%)$ \\
Nausea & $1(3.33)$ & $3(10 \%)$ \\
Constipation & $1(3.33 \%)$ & $3(10 \%)$ \\
CNS disorder & $3(10 \%)$ & $1(3.33 \%)$ \\
Somnolence & None \\
Dizziness & $3(10 \%)$ & \multicolumn{2}{|c|}{} \\
Agitation & \multicolumn{2}{|c|}{ Table 3: Frequency of overall Adverse Events Observed } \\
\hline
\end{tabular}

As per table nausea, constipation \& somnolence were reported more in combination group while dizziness, agitation in Escitalopram group. 